\title{
Genetic variability of the interpulse interval of courtship song among some European populations of Drosophila melanogaster
}

\author{
MICHAEL G. RITCHIE*†, VIKKI H. YATE \& CHARALAMBOS P. KYRIACOU \\ Department of Genetics, Adrian Building, University of Leicester, Leicester LE1 7RH, U.K.
}

\begin{abstract}
The interpulse interval of the courtship song of Drosophila melanogaster is a character which may play a significant role in mating success and reproductive isolation. Here we examine the variability of interpulse interval among replicated laboratory strains of $D$. melanogaster. There is no significant variation among populations of different geographical origin. This suggests that interpulse interval is subject to strong selection, as the populations are known to differ for other characters. One population, however, was sufficiently different to allow a genetic analysis. Reciprocal $F_{1} s$ and backcrosses implied that the variance was predominantly additive and autosomal. Possible sources of selection on interpulse interval are discussed.
\end{abstract}

Keywords: courtship song, Drosophila melanogaster, genetics, intraspecific variation, mating behaviour, speciation.

\section{Introduction}

Premating isolation between closely related animal species often arises following the evolution of new forms of mating signal and preferences (Butlin \& Ritchie, 1994). Identifying populations of a species which show divergent mating signals may help distinguish factors which contribute to this process and genetic analysis of such populations can tell us the nature and extent of genetic differences contributing to the new phenotype. Finding suitable populations for such analyses may be difficult if species-specific mating signals demonstrate low variability among populations, as might be expected. However, there is an increasing number of examples where thorough studies have identified variation (e.g. Henry \& Wells, 1990; Ritchie, 1991; Maksymovich \& Verrell, 1993; see Butlin, 1994, for a review). Genetic analyses of these populations have been limited, precluding general conclusions about their genetic architecture. For example, are new forms of mating signal or preference likely to be polygenic or due to single genes, and is sex-linkage involved? It has been argued that knowledge of the genetic changes involved may allow us to infer aspects

${ }^{*}$ Correspondence.

$\nmid$ Current address: Biological \& Medical Sciences, Bute Medical Building, University of St. Andrews, St. Andrews, Fife KY16 9TS, U.K. of the evolutionary process. Polygenic control may suggest that new forms have evolved gradually whereas single genes may imply that they can appear more suddenly (Templeton, 1981; Carson \& Templeton, 1984; Coyne, 1985, 1992a). The degree of additive, dominance and epistatic effects may indicate the likely strength and even the direction of selection (Broadhurst, 1979; Falconer, 1981; Mather \& Jinks, 1982).

Broadly speaking, there have been three approaches to studying the variability of mating behaviour in species of the melanogaster group of Drosophila. These are studies of patterns of assortative mating in the laboratory, of cuticular pheromonal variation and of courtship song. Assortative mating studies (within or between species) have detected some variation among populations (van den Berg, 1988; Welbergen et al., 1992) but the largest systematic studies of natural populations have indicated that such variation is limited (Petit et al., 1976; Henderson \& Lambert, 1982; Lambert \& Henderson, 1986). Studies of pheromonal variation have identified two major pheromonal races within Drosophila melanogaster and these have the potential to influence mating patterns between races (Jallon, 1984; Scott \& Richmond, 1988). The courtship song of D. melanogaster seems to be another important mating signal because all courtships include vigorous singing by males and some experiments have shown that female mating propensity can be enhanced by playback of artificial song (e.g. 
Bennet-Clark \& Ewing, 1969; von Schilcher, 1976; but see Kyriacou \& Hall, 1982; van den Berg, 1988; von Schilcher, 1989; Greenacre et al., 1993). Song may have influenced speciation within the subgroup as song varies substantially among species (Cowling \& Burnet, 1981) and some playback experiments show that female mating speed increases most with the correct species-specific song pattern, at least for D. melanogaster and D. simulans (Kyriacou \& Hall, 1982, 1986). Two distinct types of song are produced during courtship, pulse and hum (or 'sine') song, and most studies have concentrated on characteristics of the interpulse interval of pulse song. Ritchie \& Kyriacou (1994) found that the heritability of characteristics of both song types was low within a large laboratory collection of $D$. melanogaster, suggesting strong selection from some source. Here we examine variation in mean interpulse interval between one North African and five European populations of D. melanogaster.

\section{Materials and methods}

Flies were maintained in the laboratory at $18^{\circ}$ or $25^{\circ} \mathrm{C}$ using standard techniques (stocks were maintained at $18^{\circ} \mathrm{C}$ but moved to $25^{\circ} \mathrm{C}$ during periods of experimental work). Details of how the populations were collected can be found in Costa et al. (1992). Each population was sublined into at least two independent stocks within two generations of arriving in the laboratory. Each separate stock was maintained by simple mass transfer of a sample of flies to a fresh bottle each generation. We estimate that at least 40 flies were used for each transfer.

After around 20 generations of culture in the laboratory, the songs of males from two stocks of each population were recorded using standard procedures (Kyriacou \& Hall, 1980; Ritchie \& Kyriacou, 1994). Briefly, virgin male flies were collected and maintained individually until recorded at an age of 2-5 days using an 'Insectavox' microphone (Gorczyca \& Hall, 1987) and Revox tape recorder. All the recordings analysed here were made in a period of a few weeks under similar conditions and flies from the different stocks were interspersed in the recording sequence. We have found that interpulse interval can change slightly between different periods of recording (e.g. Ritchie \& Kyriacou, 1994) although differences between strains remain. Such environmental effects can confuse comparisons between recordings from different experimental periods; therefore we report only results from flies recorded within a single such period. This limits the number of populations that can be included in such a survey.

For each fly, at least $2 \mathrm{~min}$ of song was digitized using a Cambridge Electronic Design 1401 A/D con- verter (at a minimum of $2 \mathrm{kHz}$ after bandpass filtering at around $150 \mathrm{~Hz}$ to $1 \mathrm{kHz}$ ). Mean interpulse intervals were measured for each fly using the 'SPIKE2' software package (Copyright C.E.D.) and custom written programs. No mean based on fewer than 100 individual interpulse intervals was included in the analysis and typically around 400 would contribute to the mean per male. This analytical technique has been checked for accuracy (Ritchie \& Kyriacou, 1994).

Variation in interpulse intervals within an individual $D$. melanogaster song is not random but cycles periodically with a periodicity of around $1 \mathrm{~min}$ (Kyriacou et al., 1990). Analysing a minimum of 2 min of song per fly will have ensured that all stages of these cycles were sampled. Cycle length itself was not measured during these studies. Recordings were made over the temperature range $20-28^{\circ} \mathrm{C}\left(\right.$ mean $=24.1^{\circ} \mathrm{C}$, s.d. $\left.=1.4^{\circ} \mathrm{C}\right)$. Temperature has a large influence on interpulse interval, therefore each mean interpulse interval was corrected to $25^{\circ} \mathrm{C}$ using a highly significant linear regression coefficient prepared from a detailed study of song from a single population from N. Italy (Ritchie \& Kyriacou, 1994) which was not included in the present survey. If the relationship between interpulse interval and temperature varies substantially between populations this could introduce some error into our estimates of interpulse interval but this is not likely to be a problem as the variability in recording temperature is low.

\section{Results}

Table 1 shows the overall mean interpulse interval for each population. Variation among populations was greater than variation among stocks within a population, possibly suggesting that genetic drift within laboratory stocks reared by routine techniques does not have a major effect on mean interpulse interval. Variation among populations was not statistically significant when tested against the variation among stocks.

Apart from one population, Rethimnon, from the Greek islands, the mean interpulse interval per population seems remarkably stable. The mean interpulse interval of Rethimnon is $2-3 \mathrm{~ms}$ different from the other populations, which themselves vary by only around $0.5 \mathrm{~ms}$. For comparison, the mean difference between $D$. melanogaster and $D$. simulans is approximately $15 \mathrm{~ms}$ and no pair of species from the melanogaster group differs by less than this (Cowling \& Burnet, 1981). While it is noticeable that the range of interpulse intervals within a population is large (Table 1 ), the coefficients of variation are all low (averaging 7 per cent). Thus interpulse interval seems somewhat stereotyped. 
Table 1 Overall mean interpulse interval (IPI) per population $\dagger$

\begin{tabular}{|c|c|c|c|c|c|c|}
\hline Population & $N$ & Mean IPI & S.E. & $\mathrm{CV}(\%)$ & \multicolumn{2}{|c|}{ Range } \\
\hline $\begin{array}{l}\text { Casablanca } \\
\text { (Morocco) }\end{array}$ & 12 & 35.995 & 0.672 & 6.47 & \multicolumn{2}{|c|}{$32.201-39.525$} \\
\hline $\begin{array}{l}\text { Leiden } \\
\text { (Holland) }\end{array}$ & 7 & 35.630 & 1.090 & 8.11 & \multicolumn{2}{|c|}{$30.470-39.500$} \\
\hline $\begin{array}{l}\text { Bologna } \\
\text { (Italy) }\end{array}$ & 16 & 35.779 & 0.572 & 6.39 & \multicolumn{2}{|c|}{$31.212-38.424$} \\
\hline $\begin{array}{l}\text { Sibari } \\
\text { (Italy) }\end{array}$ & 17 & 35.375 & 0.529 & 6.17 & \multicolumn{2}{|c|}{$30.620-39.013$} \\
\hline $\begin{array}{l}\text { Andros } \\
\text { (Greece) }\end{array}$ & 19 & 35.557 & 0.663 & 8.13 & \multicolumn{2}{|c|}{$31.895-44.198$} \\
\hline $\begin{array}{l}\text { Rethimnon } \\
\text { (Greece) }\end{array}$ & 22 & 32.907 & 0.506 & 7.21 & \multicolumn{2}{|c|}{$30.062-40.041$} \\
\hline \multicolumn{7}{|c|}{ Analysis of variance: } \\
\hline Source of $v$ & varia & $\mathrm{Me}$ & ean square & d.f. & $F$ & $P$ \\
\hline \multirow{2}{*}{\multicolumn{3}{|c|}{$\begin{array}{l}\text { Populations } \\
\text { Stocks (populations) }\end{array}$}} & 25.808 & 5 & 3.34 & 0.087 \\
\hline & & & 7.721 & 6 & 1.28 & 0.274 \\
\hline \multicolumn{3}{|l|}{ Error } & 6.011 & 81 & & \\
\hline
\end{tabular}

†Calculated by averaging the mean IPIs of each male (column $N$ gives number of males per population).

$\mathrm{CV}$ is the coefficient of variation of these means, S.E. the standard error.

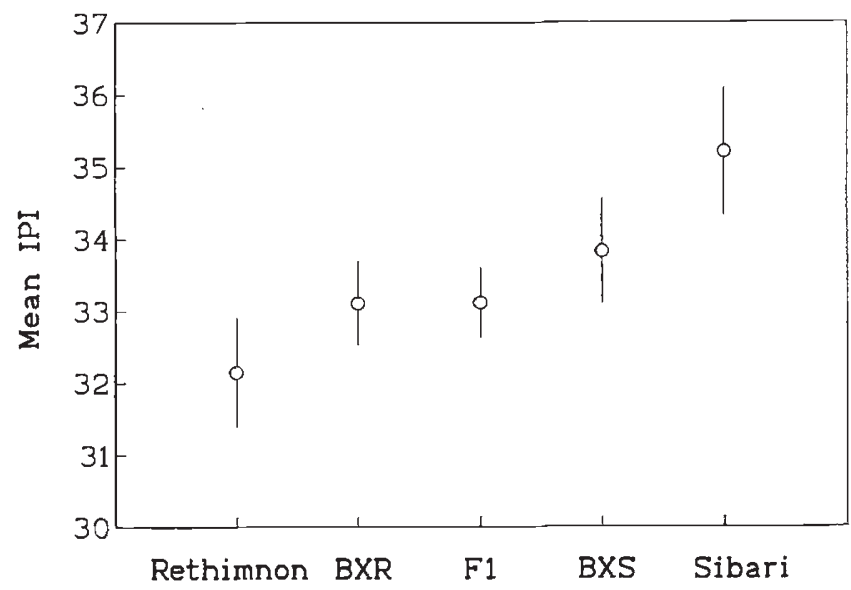

Fig. 1 Overall mean interpulse interval amongst Rethimnon, Sibari, $F_{1}$ and backcross genotypes $\left(F_{1}\right.$ males $\times$ Rethimnon or Sibari females). Error bars are 95 per cent confidence intervals.

To examine the genetic basis of the unusual phenotype of flies from Rethimnon, these were crossed to the Sibari population. Figure 1 shows the mean interpulse interval of $F_{1}$ and backcross genotypes. The difference between these populations was clearly genetic in origin. Table 2 presents estimates of the additive and dominance components and summarizes tests of an
Table 2 Genetic components of interpulse interval for Rethimnon and Sibari populations

\begin{tabular}{|c|c|c|c|c|c|}
\hline Genotype & $N$ & $\mathrm{Vx}$ & Weight & Observed & Expected \\
\hline Sibari & 12 & 0.149 & 6.711 & 32.149 & 32.441 \\
\hline Rethimnon & 9 & 0.199 & 5.025 & 35.210 & 35.049 \\
\hline$F_{1}$ & 24 & 0.062 & 16.129 & 33.115 & 33.189 \\
\hline$B X S$ & 19 & 0.087 & 11.494 & 33.107 & 32.815 \\
\hline$B X R$ & 16 & 0.137 & 7.299 & 33.834 & 34.119 \\
\hline \multicolumn{3}{|c|}{ Parameter } & \multicolumn{2}{|c|}{ Fitted value } & S.E. \\
\hline \multirow{3}{*}{\multicolumn{3}{|c|}{$\begin{array}{l}\text { m (midpoint) } \\
\text { [d] (additive) } \\
{[\mathrm{h}] \text { (dominance) }}\end{array}$}} & \multirow{3}{*}{\multicolumn{2}{|c|}{$\begin{array}{r}33.745 \\
-1.304 \\
-0.556\end{array}$}} & 0.258 \\
\hline & & & & & 0.250 \\
\hline & & & & & 0.384 \\
\hline \multicolumn{3}{|c|}{$\begin{array}{l}\text { Scaling tests } \\
\mathrm{A}=0.950 \pm 0.748 \\
\mathrm{~B}=-0.657 \pm 0.899 \\
\text { Joint: } \chi_{[2]}^{2}=2.363, \text { n.s. }\end{array}$} & & & \\
\hline
\end{tabular}

additive-dominance model (after Mather \& Jinks, 1977), which fitted the data well. Only the additive component was significant (Table 2), there was no difference between reciprocal $F_{1} \mathrm{~s}(\mathrm{R} \times \mathrm{S}=33.000 \mathrm{~ms}$, $N=12$, S.E. $=0.401 ; \quad \mathrm{S} \times \mathrm{R}=33.230 \mathrm{~ms}, \quad N=12$, S.E. $=0.307 ; t=0.455$, n.s.) and the backcross genotypes were continuously distributed (Fig. 2). It therefore seems most probable that the Rethimnon song difference is an autosomal polygenic additive character, although these data do not allow us to reject the possibility of ambidirectional dominance.

\section{Discussion}

Henderson \& Lambert (1982) found no significant assortative mating between stocks of $D$. melanogaster taken from world-wide populations (see also Lambert \& Henderson, 1986) and attributed this to stabilizing selection acting on the 'Specific Mate Recognition System' (Paterson, 1985). It does seem likely that behaviours important to mating success will be subject to strong selection and coevolution between signals and preferences would be expected to generate a degree of stabilizing selection which would reduce the genetic variability within populations. However, in the absence of external sources of selection on the communication system (e.g. environmental selection on signal propagation), there is no reason to suppose that truly disjunct geographical populations should evolve to any single particular phenotype as long as preferences and signals are in balance within a population. Indeed, theory shows that a direct viability optimum on a male mating signal imposed by the environment can still result in isolated populations (with the same environment) showing a range of combinations of trait and preferences (Lande, 1981). Stable equilibria occur 


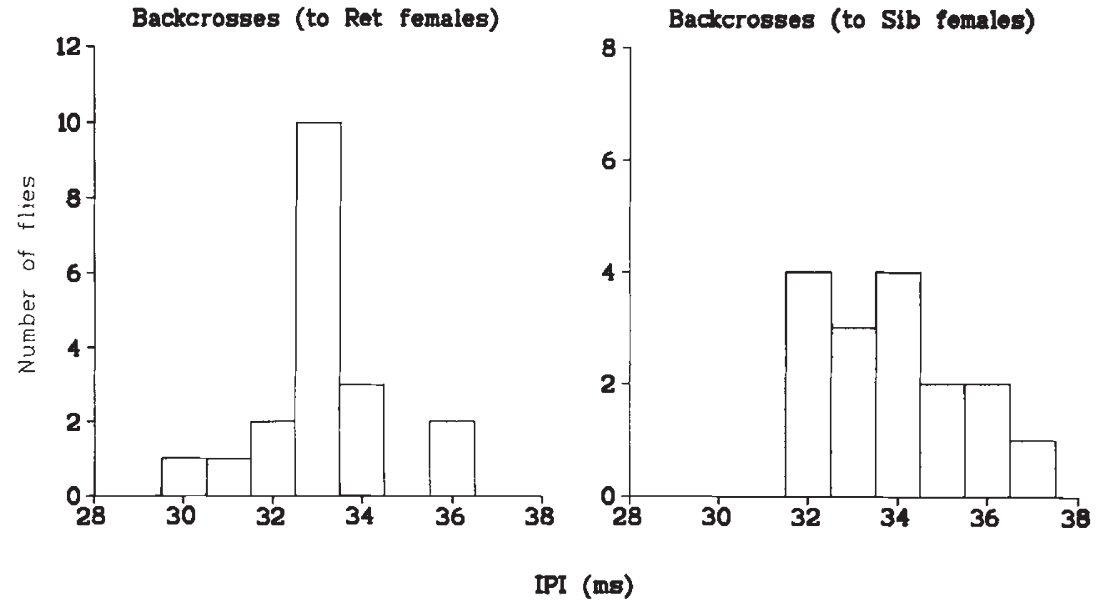

Fig. 2 Distribution of mean interpulse interval within the backcross genotypes $\left(F_{1}\right.$ males $\times$ Rethimnon or Sibari females). where selection from viability and preference counterbalance.

The relatively low variability of interpulse interval in $D$. melanogaster is therefore something of a surprise. The present study found little variation among stocks recently originating from six European populations. Kawanishi \& Watanabe (1980) obtained similar results comparing 11 Japanese and three non-Japanese laboratory strains. Van den Berg (1988) found a difference of almost $3 \mathrm{~ms}$ in the mean interpulse intervals of single strains originating from Africa and South America. Comparisons between different studies are not valid due to variation in techniques and environmental effects.

Limited variability could occur if distinct geographical populations are genetically homogeneous due to extensive contemporary gene flow or were all recently colonized from a common source. This seems unlikely as D. melanogaster is typically relatively variable for morphological and genetic markers (Singh \& Long, 1992) and the populations studied here are known to vary for at least one genetic marker (Costa et al., 1992). Nevertheless, the combination of relatively recent colonization from Africa (Lachaise et al., 1988) and large migration rates within Europe could contribute to the results found here. The fact that $D$. melanogaster normally shows more variation among populations than D. simulans (Singh \& Long, 1992), yet the opposite pattern may be found for interpulse interval is extremely interesting (Kawanishi \& Watanabe, 1980; Kyriacou \& Hall, 1986). Selection on song must differ between the species.

Low variation amongst populations of $D$. melanogaster would be less surprising if selection is directional, despite the prediction of stabilizing selection for mating signals. This could arise if, for example, female mating propensity were simply a product of the amount of song heard. Males would then be under strong directional selection for reduced interpulse interval, maximizing song output. Interpulse interval may then reflect a physiologically determined upper limit of song production which might be expected to vary less among populations than signal-preference equilibrium states. An artificial selection experiment has been more successful at lengthening than shortening mean interpulse interval (M. G. Ritchie, unpublished data). However, the predominantly additive genetic variation among populations found here would not be predicted under such a selection scheme as strong directional selection is expected to produce a directionally dominant genetic architecture (Broadhurst, 1979; Mather \& Jinks, 1982). Cowling (1980) also found only additive genetic variation for $D$. melanogaster interpulse interval in a diallel analysis of variability among laboratory strains (one originally from Africa showed a low interpulse interval but the history of the stocks studied was not clear).

Another possibility is that the strongest source of selection on male song is indirect, i.e. from sources other than female mating preferences. Environmental sources of selection on muscle physiology will presumably be quite stable in the laboratory which could reduce variation among stocks. Artificial song playback experiments with $D$. melanogaster typically show low resolution of female preferences and seem unlikely to reveal whether selection from female preferences is directional or stabilizing. It is difficult to distinguish if this is because female song preferences are truly weak, because of poor experimentation (e.g. song synthesis), or if the species is simply not well suited to such experiments. We suspect the latter may be likely.

That the slightly divergent song found here was due to quantitative additive genetic variation suggests that 
this new form has arisen gradually. However, relatively few genes could be involved. The lack of sex-linkage does not support the contention that new mating signals may be predominantly sex-linked (Ewing, 1969). Charlesworth et al. (1987) found little evidence to support this when reviewing behavioural data. In general, sex-linkage may be more prevalent for sources of postmating than premating isolation (Coyne, 1992b).

It is not known if flies from Rethimnon show any premating isolation from the other $D$. melanogaster populations. White et al. (1994) have recently argued that Specific Mate Recognition Systems may often retain their cohesive qualities across a species despite showing variability in their components. This is of course true; many aspects of mating behaviour may vary widely without constituting new 'systems' of mate recognition and song is only one of many such factors in Drosophila. However, White et al. (1994) take this argument further when they argue that the concept of variability cannot be applied to mate recognition systems [e.g. 'the concept of variation cannot be used in relation to the systems (SMRSs) themselves']. This is incompatible with the observation that many species are composed of clearly differentiated subforms including significant components of mating behaviours, often evidenced by strong assortative mating between forms (e.g. Ritchie, 1991; Maksymovich \& Verrell, 1993). These forms represent the raw material of evolutionary change and speciation must have often originated from such races. They therefore deserve our special attention.

\section{Acknowledgements}

We acknowledge a grant from the SERC (GRF 43765) which supported this work and Alex Peixoto for his interest and ideas.

\section{References}

BENNET-CLARK, H. C. AND EWING, A. W. 1969. Pulse interval as a critical parameter in the courtship song of Drosophila melanogaster. Anim. Behav., 17, 755-759.

BROADHURST, P. L. 1979. The experimental approach to behavioral evolution. In: Royce, J. R. and Mos, L. P. (eds) Theoretical Advances in Behavior Genetics, pp. 43-100. Sijthoff \& Noordhoff, Alphen aan den Rijn, The Netherlands.

BUTLIN, R. K. 1994. Genetic variation in mating signals and responses. In: Masters, J., Lambert, D. M. and Spencer, H. (eds) Speciation and the Recognition Concept: Theory and Application. Johns Hopkins University Press, Baltimore, MD. (in press).
BUTLIN, R. K. AND RITCHIE, M. G. 1994. Mating behaviour and speciation. In: Slater, P. J. B. and Halliday, T. R. (eds) Behaviour and Evolution. Cambridge University Press, Cambridge (in press).

CARSON, H. L. AND TEMPLETON, A. R. 1984. Genetic revolutions in relation to speciation phenonema: the founding of new populations. Ann. Rev. Ecol. Syst., 15, 97-131.

CHARLESWORTH, B., COYNE, J. A. AND BARTON, N. H. 1987. The relative rates of evolution of sex chromosomes and autosomes. Am. Nat., 130, 113-146.

COSTA, R., PEIXOTO, A. A., BARBUJAN1, G. AND KYR1ACOU, C. P. 1992. A latitudinal cline in a Drosophila clock gene. Proc. $R$. Soc. Lond. B., 250, 43-49.

CoWLING, D. E. 1980. The genetics of Drosophila melanogaster courtship song - diallel analysis. Heredity, 45, 401-403.

COWLING, D. E. AND BURNeT, B. 1981. Courtship song and genetic control of their acoustic characteristics in sibling species of the Drosophila melanogaster subgroup. Anim. Behav., 29, 924-935.

COYNE, J. A. 1985. Genetic studies of three sibling species of Drosophila with relationship to theories of speciation. Genet. Res., 46, 169-192.

COYNE, J. A. 1992a. Genetics and speciation. Nature, 355, 511-515.

COYNE, J. A. 1992b. Genetics of sexual isolation in females of the Drosophila simulans complex. Genet. Res.., 60, 25-31.

EwING, A. w. 1969. The genetic basis of sound production in Drosophila pseudoobscura and D. persimilis. Anim. Behav., 17, 555-560.

FALCONER, D. S. 1981. Introduction to Quantitative Genetics, 2nd edn. Longman, London.

GORCZYCA, M. AND HALL, J. C. 1987. The Insectavox, an integrated device for recording and amplifying courtship songs of Drosophila. Dros. Inf. Serv., 66, 157-160.

GREENACRE, M., RITCHIE, M. G., BYRNE, B. C. AND KYRIACOU, C. P. 1993. Female song preferance and the period gene of Drosophila melanogaster. Behav. Genet., 23, 85-90.

HENDERSON, N. R. AND LAMBERT, D. M. 1982. No significant deviation from random mating of worldwide populations of Drosophila melanogaster. Nature, 300, 437-440.

HENRY, C. S. AND WELLS, M. M. 1990. Geographical variation in the song of Chrysoperla plorabunda (Neuroptera: Chrysopidae) in North America. Ann. Entomol. Soc. Am., 83, 317-325.

JALLON, J.-M. 1984. A few chemical words exchanged by Drosophila during courtship and mating. Behav. Genet., 14, 441-478.

KAWANISHI, M. AND WATANABE, T. K. 1980. Genetic variations of courtship song of Drosophila melanogaster and $D$. simulans. Jpn. J. Genet., 55, 235-240.

KYR1ACOU, C. P. AND HALL, J. C. 1980. Circadian rhythm mutations in Drosophila melanogaster affect short-term fluctuations in the male's song. Proc. Natl. Acad. Sci. U.S.A., 77, 6729-6733.

KYR1ACOU, C. P. AND HALL, J. C. 1982. The function of courtship song rhythms in Drosophila. Anim. Behav., 30, 794-801.

KYRIACOU, C. P. AND HALL, J. C. 1986. Interspecific genetic control of courtship song production and reception in Drosophila. Science, 232, 494-497. 
KYRIACOU, C. P., VAN DEN BERG, M. AND HALL, J. C. 1990. Courtship song rhythms in wild-type and period mutant Drosophila revisited. Behav. Genet., 20,631-658.

LACHAISE, D., CARIOU, M.-L., DAVID, J. R., LEMEUNIER, F., TSACAS, L. AND ASHBURNER, M. 1988. Historical biogeography of the Drosophila melanogaster species subgroup. Evol. Biol., 22, 159-225.

LAMBERT, D. M. AND HENDERSON, N. R. 1986. The stability of the specific-mate recognition system of Drosophila melanogaster. Behav. Genet., 16, 369-373.

LANDE, R. 1981. Models of speciation by sexual selection on polygenic traits. Proc. Natl. Acad. Sci. U.S.A., 78, 3721-3725.

MAKSYMOVITCH, E. AND VERRELL, P. A. 1993. Divergence of mate recognition systems among conspecific populations of the plethodontid salamander Desmognathus santeetlah. Biol. J. Linn. Soc., 49, 19-29.

MATHER, K. AND JINKS, J. L. 1977. Introduction to Biometrical Genetics, 3rd edn. Chapman and Hall, London.

MATHER, K. AND JINKS, J. L. 1982. Biometrical Genetics, 3rd edn. Chapman and Hall, London.

PATERSON, H. E. H. 1985. The recognition concept of species. In: Vrba, S. (ed.) Species and Speciation, pp. 21-29. Transvaal Museum Monograph No. 4, Transvaal Museum, Pretoria, South Africa.

PETIT, C., KITAGAWA, O. AND TAKAmURA, T. 1976. Mating system between Japanese and French geographic strains of Drosophila melanogaster. Jpn. J. Genet., 51, 99-108.

RITCHIE, M. G. 1991. Female preference for 'song races' of Ephippiger ephippiger (Orthoptera: Tettigoniidae). Anim. Behav., 42, 518-520.
RITCHIE, M. G. AND KYRIACOU, C. P. 1994. The genetic variability of courtship song in a population of Drosophila melanogaster. Anim. Behav. (in press).

SCOTT, D. AND RICHMOND, R. C. 1988. A genetic analysis of malepredominant pheromones in Drosophila melanogaster. Genetics, 119, 639-646.

SINGH, R. S. AND LONG, A. D. 1992. Geographic variation in Drosophila: from molecules to morphology and back. Trends Ecol. Evol., 7, 340-345.

TEMPLETON, A. R. 1981. Mechanisms of speciation - a population genetics approach. Ann. Rev. Ecol. Syst., 12, 23-48.

VAN DEN BERG, M. J. 1988. Assortative mating in Drosophila melanogaster and among three species of the melanogaster subgroup. Ph.D. Thesis, University of Groningen, The Netherlands.

VON SCHILCHER, F. 1976. The function of pulse song and sine song in the courtship of Drosophila melanogaster. Anim. Behav., 24, 622-625.

VON SCHILCHER, F. 1989. Have cycles in the song of Drosophila been detected? Trends Neurosci., 12, 311-313.

WELBERGEN, P., VAN DIJKEN, F., SCHARLOO, W. AND KOHLER, W. 1992. The genetic basis of reproductive isolation between Drosophila melanogaster and D. simulans. Evolution, 46, 1385-1398.

WhiTE, C. S., LAMBERT, D. M. AND FOSTER, S. P. 1994. Chemical signals and the recognition concept. In: Masters, J., Lambert, D. M. and Spencer, H. (eds) Speciation and the Recognition Concept: Theory and Application, Johns Hopkins University Press, Baltimore, MD. (in press). 